\title{
EVALUATION OF CHRONIC TOXICITY OF GOWRI CHINTHAMANI CHENDURAM IN WISTAR ALBINO RATS
}

\author{
P. Elankani', G. Dayanand Reddy², R. Ganesan², B. Rama Devi², G.V. Narasimha Kumar ${ }^{3}$ \\ 1. Siddha Clinical Research Unit, Palayamkottai, Tirunelveli, Tamilnadu-627002. \\ 2. Siddha Central Research Institute, Arumbakkam, Chennai, Tamilnadu -600106. \\ 3. Dr. Anjali Chatterjee Regional Research Institute for Homoeopathy, Kolkata, West Bengal-700035.

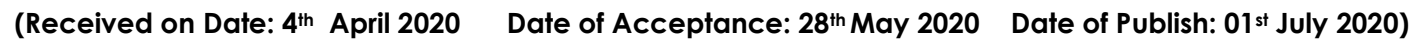 \\ Email id: ramasamba527@gmail.com
}

\begin{abstract}
Aim and Objectives: The aim of the present study was to carry out 90 days repeated oral toxicity of Gowri chinthamani chenduram (GCC) in Wistar albino rats and to assess in a 30 days recovery period for delayed onset of any toxicity of Gowri chinthamani chenduram. Methods: Cronic toxicity of Gowri chinthamani chenduram was evaluated in wistar albino rats with reference to haematological, bio-chemical and histopathological studies. Results: No GCC-related changes in body weights, food and water intake, cage side observations, clinical observations, clinical pathology, mortality, macroscopic examinations and organ histopathology were noted during treatment period and post recovery period. Conclusion: Based on the results of this study, the no-observed-adverse-effect-level (NOAEL) of Gowri chinthamani chenduram in rats is $>400 \mathrm{mg} / \mathrm{kg} /$ day when administered orally for 90 days
\end{abstract}

Key words: Cronic toxicity, Gowri chinthamani chenduram, metallomineral, Siddha. 


\section{Introduction}

India has different recognized systems of medicine. They are Ayurveda, Siddha, Unani, Yoga, Naturopathy Homoeopathy and Sowa Rigpa 1. Among them Siddha is the unique system of medicine "Siddha" means "established truth" 2. Siddha system of medicine is claimed to alleviate the root cause of the diseases by maintaining the ratio of Vatham, Pitham and Kapham. In this system of medicine the commonly used formulations in combination with minerals are Parpam (mineral/metallic oxides), Chendhooram (mineral/metallic sulphides), Chunnam (caustic or major oxides) and Pathangam (sublimation). Among them Parpam and Chenduram type of medicines are widely used, having potential therapeutic values ${ }^{3}$.

Gowri chinthamani chenduram (GCC) is a Siddha metallomineral formulation and it contains Mercury, Sulphur and Borax 4 . Gowri chinthamani chenduram at a dose of $100-200 \mathrm{mg}$ thrice a day with honey is one of the best and potent compound drugs for osteoarthritis mentioned in Agasthiar Vaidhya Kaviyam - 1500 5. It has a long history in Siddha system of medicine for various ailments especially for the treatment of inflammation ${ }^{6}$. GCC is also known to cure 18 types of colic, 16 types of gastritis, chronic fevers, rat bite, pneumonia, bronchitis, dyspnoea, Tuberculosis (TB), bronchial asthma, piles, jaundice, inflammation of male and female genital organs accompanied by severe pain, pain in the tongue and ulcerative bites ${ }^{7}$. The duration of the treatment is depends on the severity from 30 - 60 days 6. As mentioned earlier, GCC is a metallomineral formulation and is being used for prolong period to treat several diseases. Chronic usage of these metal formulation may grounds toxic effects, hence, the need for its safety has to be ascertained. So the present work was carried out in wistar albino rats by following OECD guideline $408^{7}$.

\section{Materials and Methods:}

Procurement of Gowri chinthamani chenduram: Gowri chinthamani chenduram was collected from The Indian Medical Practitioner's Co-operative Pharmacy \& Stores LTD (GMP certified) Thiruvaanmiyur, Chennai.

Preparation of Vehicle: The vehicle in the study was prepared as follows;

$5 \mathrm{ml}$ of dabur honey diluted with $95 \mathrm{ml}$ R.O water and made the volume up to $100 \mathrm{ml}$ (5\%v/y). 0.5\% CMC was prepared by triturating the $500 \mathrm{mg}$ of $\mathrm{CMC}$ in $100 \mathrm{ml}$ of $5 \% \mathrm{v} / \mathrm{v}$ honey till formation of a clear solution.

Preparation of Gowri chinthamani chenduram: The test doses were prepared by triturating a weighed quantlity of test drug in required volume of $0.5 \%$ carboxy methyl cellulose (CMC) prepared in $5 \%$ $v / v$ honey to obtain a concentration of 40 $\mathrm{mg} / \mathrm{kg}, 200 \mathrm{mg} / \mathrm{kg}$ and $400 \mathrm{mg} / \mathrm{kg}$.

Animals and Husbandry: A total of 80 wistar albino rats (40/sex) of 5 to 6 weeks age were received from TANUVAS, Chennai, Tamil Nadu. The body weight variation of the animals selected for the study on the day of randomization did not exceed $\square \square 20 \%$ of the mean body weight of each sex. This study was performed as per the recommendations of the Committee for the Purpose of Control 2020 July Edition | www.jbino.com | Innovative Association 
and Supervision of Experiments on Animals (CPCSEA) guidelines for

Laboratory Animal Facility after approval of Institutional Animal Ethics Committee (IAEC) of Siddha Central Research Institute, Central Council for Research in Siddha (Ministry of AYUSH), Arumbakkam, Chennai-106. The study was approved by the Institutional Ethical Committee (164/PHARMA/SCRI/2017).

Feed and water were provided ad libitum, except on study day (SD) 30-31, 6061, 90-91 (before terminal sacrifice) and SD 119-120 (before recovery sacrifice) when food-fasting was implemented and rats were fasted for 12 hours before termination at those 4 occasions. The animals were maintained in polypropylene cages at room temperature $18-25^{\circ} \mathrm{C}$, humidity 30 to $65 \%$ and light cycle 12-hour light/12-hour dark.

Chemicals: The chemicals used in this study such as Carboxy methyl cellulose, Sodium chloride, Formaldehyde, Anesthetic ether and Sodium ethylenediaminetetraacetic acid (sodiumEDTA) of analytical grade were purchased from Theres scientific works, Chennai.

\section{Dose calculation of Gowri chinthamani} chenduram: The clinical dose of Gowri chinthamani chenduram is $200 \mathrm{mg}$. The animal (rat) doses are calculated as per the FDA guidelines ${ }^{8}$ and the calculated therapeutic dose (TD) was found to be $40 \mathrm{mg} / \mathrm{kg}$ of body weight. In the present study to evaluate the dose correlated effects, 5 times TD and 10 times TD i.e. 200 $\mathrm{mg} / \mathrm{kg}$ \& $400 \mathrm{mg} / \mathrm{kg}$ of bodyweight were chosen correspondingly.

Experiment Design: The present study was carried out according to OECD 408 guidelines. Animals were initially divided into four groups, each group contains 20 animals (10/sex) based upon descending body weights and physical examinations. Male and females were randomized into groups separately based on bodyweight. After the randomization process, each study animal was assigned a unique number and identified by a picric acid mark. Group-l served as normal control, Group-II, Group-III and Group-IV administered with test drug at a doses of $40 \mathrm{mg} / \mathrm{kg}, 200 \mathrm{mg} / \mathrm{kg}$ and 400p.o. mg/kg respectively for 90 days. At $90^{\text {th }}$ day $50 \%$ of the experimental animals (40 animals) in each group were subjected to euthanasia. The necropsy was carried out on all euthanized animals and the organs were isolated and observed macroscopically for abnormalities. After 30 days of post treatment the remaining half animals (40animals) were euthanized and organs were collected and observed macroscopically for abnormalities. The organs of treatment and post treatment were preserved in $10 \%$ neutral formalin and were subjected for histopathology.

Observations: Cage side observations included observation for mortality, morbidity, general health, and signs of toxicity. Clinical observations included evaluation of skin and fur characteristics, eye and mucous membrane, sensory responses and 
reflexes, respiratory and autonomic effects, motor activity and behavior patterns.

Hematology: The hematology
parameters viz., hemoglobin
concentration (HB), packed cell volume
(PCV), total red blood cell count (RBC),
total white blood cell count (WBC) and
platelet count (PLT) were analyzed.

Serum Biochemistry: Following serum biochemical parameters were estimated using RA-50 auto analyzer(Bayer).Glucose, Alkaline phosphatase Total proteins, Albuminn, Creatine phosphotase, Uric acid and Calcium.

Histopathology: All tissue samples from each group viz., brain, pancreas, adrenal glands, heart, thymus, liver, kidneys, spleen, stomach, testes / ovaries, epididymides/ uterus, sciatic nerve, skin and femur bone from each group test animals(1/sex) were processed and evaluated. Those tissue samples were embedded in paraffin, sectioned, stained with hematoxylin and eosin and examined microscopically by a board-certified veterinary pathologist.

\section{Statistical Analysis:}

Body weights, food intake, water intake, relative organ weights, and clinical pathology data were analyzed statistically. All the data was expressed as mean \pm SEM. Statistical significance between more than two groups was tested using one-way ANOVA followed by Tukey's post hoc using Graph pad prism version-5. The significance level was set at $P<0.05$ for all tests. Group II, III, and IV will be statistically compared with Group I to find the treatment related effects 9 .

\section{Results and Discussions:}

The dose volume was $1 \mathrm{ml} / 100 \mathrm{~g}$ body weight per day for all animals. The total volume of administration was calculated based on the weekly body weights of the animals. In the present study changes in body weight, feed and water consumption, biochemical parameters and histopathological studies were carried out and the results are expressed in the form of tables and figures.

Blood urea, Creatinine; Total Cholesterol,T

No compound-relatéd mortality or signs of toxicity were noted. Other observations noted included alopecia, excessive grooming, Straube's phenomenon, abscess formation and hyperactivity; these observations were considered unrelated to treatment because they occurred in both the compound-treated and control groups or only appeared sporadically in low incidence throughout the study with no correlation to treatment or sex.

No compound-related body weight changes were noted. No significant differences were noted in total body weight change over the course of the study for either sex. Group summary of body weight data for males and females are presented in table 1 and 2 respectively.

A significant change in the feed intake was not observed in animals during treatment period and post recovery period between the groups. The data are presented in table 3.

No significant change in the water intake was observed in animals during treatment 
period and post recovery period between the groups. The data are presented in table 4.

The clinical pathology evaluation and data reports are presented in table 5-12. No compound-related changes in hemoglobin concentration, packed cell volume, total red blood cell count, total white blood cell count and platelet count were noted (table 5-8). No compoundrelated changes in serum glucose, serum Urea, serum Creatinine, serum Total Cholesterol, serum Triglycerides, serum HDL, serum LDL, serum Total bilirubin, serum SGOT, serum SGPT, serum ALP, serum Total proteins, serum Albumin, serum CRP, serum Uric acid, serum Calcium (table 912) were noted.

Macroscopic observations were listed in table 13. All findings listed in table 13 were considered incidental because they occurred in frequently, in both treated and control animals, exhibited no dose relationship.

The histopathology of brain and stomach (glandular \& non glandular) shown normal characteristic features with regular cell arrangements at the end of the treatment $\left(90^{\text {th }}\right.$ day) and post recovery period $\left(120^{\text {th }}\right.$ day) in both control and GCC treated animals. Liver histopathology showed congestion, multifocal moderate vesicular (micro to macro) fatty degeneration of hepatocytes. The histopathology of heart in all groups shown normal characteristic features at the end of the treatment $190^{\text {th }}$ day) and post recovery period $\left(120^{\text {th }}\right.$ day). Congestion and mild tubular epithelial cell degeneration was noticed in the histopathology of kidneys of control and test drug GCC treated animals. Pulmonary congestion, haemorrhages, peribronchiolar and interstitial mononuclear cell infiltration was observed in the lungs histopathology of both control and test drug treated animals at end of the treatment $\left(90^{\text {th }}\right.$ day) and post recovery period $\left(120^{\text {th }}\right.$ day). Congestion was noticed in the spleen of group-II (animal No .GCC20; dose $40 \mathrm{mg} / \mathrm{kg}$ ) at post recovery period $\left(120^{\text {th }}\right.$ day). The histopathology of thymus has shown mild lymphoid cell depletion in group-III (animal No.66; dose $200 \mathrm{mg} / \mathrm{kg}$ ) and group-IV (animal No.37; dose $400 \mathrm{mg} / \mathrm{kg}$ ) animals at end of the treatment. No abnormalities and damaged cells were noticed in the histopathology of sciatic nerve, adrenal gland, spleen, skin, femur bone, eye, ovary and uterus. Images of the organs were shown in figure 1 and 2 at end of the treatment and post recovery period respectively. 
Table1. Effect of GCC on body weight (g) of male rats

\begin{tabular}{|c|c|c|c|c|c|c|}
\hline \multirow[t]{2}{*}{ S.NO. } & \multirow[t]{2}{*}{ Group } & \multicolumn{4}{|c|}{ Treatment Period } & \multirow{2}{*}{\begin{tabular}{|l|} 
Post recovery \\
Period
\end{tabular}} \\
\hline & & $0^{\text {th }}$ Day & 30 $^{\text {th }}$ Day & $6^{\text {th }}$ Day & 90 $^{\text {th }}$ Day & \\
\hline 1 & I & $216.0 \pm 11.77$ & $246.1 \pm 28.35$ & $272.5 \pm 30.98$ & $304.5 \pm 34.20$ & $325.5 \pm 12.95$ \\
\hline 2 & II & $224.3 \pm 9.804$ & $269.2 \pm 12.02$ & $312.4 \pm 15.01$ & $333.2 \pm 14.81$ & $351.6 \pm 23.57$ \\
\hline 3 & III & $224.7 \pm 4.847$ & $271.1 \pm 4.927$ & $314.8 \pm 6.751$ & $336.4 \pm 6.822$ & $353.5 \pm 11.59$ \\
\hline 4 & IV & $221.3 \pm 6.683$ & $276.9 \pm 4.334$ & $321.5 \pm 4.865$ & $338.3 \pm 5.880$ & $362.0 \pm 6.988$ \\
\hline
\end{tabular}

All values were expressed as Mean \pm S.E.M; $n=10$

Table 2. Effect of GCC on body weight (g) of female rats

\begin{tabular}{|c|c|c|c|c|c|c|}
\hline \multirow{2}{*}{ S.NO } & \multirow[t]{2}{*}{ Groups } & \multicolumn{4}{|c|}{ Treatment Period } & \multirow{2}{*}{$\begin{array}{l}\text { Post Recovery } \\
\text { Period } \\
\mathbf{1 2 0}^{\text {th }} \text { Day }\end{array}$} \\
\hline & & $0^{\text {th }}$ Day & $3^{\text {th }}$ Day & 60 $^{\text {th }}$ Day & 90 ${ }^{\text {th }}$ Day & \\
\hline & I & $171.1 \pm 6.92$ & $201.0 \pm 5.90$ & $207.8 \pm 5.08$ & $215.9 \pm 5.982$ & $229.3 \pm 14.40$ \\
\hline & & 3 & 3 & 5 & & \\
\hline 2 & II & $\begin{array}{l}168.9 \pm 6.16 \\
3\end{array}$ & $\begin{array}{l}201.4 \pm 5.02 \\
7\end{array}$ & $\begin{array}{l}211.2 \pm 4.99 \\
1\end{array}$ & $222.2 \pm 5.921$ & $232.0 \pm 5.779$ \\
\hline 3 & III & $\begin{array}{l}166.8 \pm 3.99 \\
1\end{array}$ & $\begin{array}{l}185.9 \pm 21.2 \\
3\end{array}$ & $\begin{array}{l}171.3 \pm 30.2 \\
7\end{array}$ & $160.0 \pm 35.55$ & $229.3 \pm 16.25$ \\
\hline 4 & IV & $\begin{array}{l}183.6 \pm 8.88 \\
7\end{array}$ & $\begin{array}{l}195.4 \pm 4.76 \\
8\end{array}$ & $\begin{array}{l}183.3 \pm 20.8 \\
9\end{array}$ & $190.0 \pm 21.67$ & $225.0 \pm 5.447$ \\
\hline
\end{tabular}

All values were expressed as Mean \pm S.E.M; $n=10$ 
Table 3. Effect of GCC on Feed intake (g) of experimental animals

\begin{tabular}{|c|c|c|c|c|}
\hline \multirow[t]{2}{*}{ Weeks } & \multicolumn{4}{|c|}{ Treatment Groups } \\
\hline & Group I & Group II & Group III & Group IV \\
\hline \multicolumn{5}{|c|}{ Treatment Period } \\
\hline Week 1 & $235 \pm 34.74$ & $255 \pm 45.43$ & $242 \pm 38.49$ & $302 \pm 9.09$ \\
\hline Week 2 & $323.5 \pm 6.15$ & $344 \pm 4.28$ & $344 \pm 6.95$ & $331.5 \pm 3.47$ \\
\hline Week 3 & $343.5 \pm 6.15$ & $361.5 \pm 2.41$ & $366.5 \pm 1.34$ & $351 \pm 4.81$ \\
\hline Week 4 & $342.5 \pm 0.27$ & $362.5 \pm 1.87$ & $335.5 \pm 5.08$ & $356 \pm 1.60$ \\
\hline Week 5 & $322.5 \pm 1.87$ & $341.5 \pm 2.41$ & $334 \pm 2.14$ & $301.5 \pm 9.34$ \\
\hline Week 6 & $338 \pm 3.21$ & $368.5 \pm 2.41$ & $326.5 \pm 0.27$ & $343 \pm 0.53$ \\
\hline Week 7 & $338.5 \pm 6.68$ & $364.5 \pm 0.80$ & $336 \pm 3.21$ & $340.5 \pm 9.35$ \\
\hline Week 8 & $338.5 \pm 5.61$ & $368.5 \pm 1.34$ & $332.5 \pm 0.27$ & $343.5 \pm 7.75$ \\
\hline Week 9 & $351.5 \pm 1.34$ & $365 \pm 2.67$ & $315 \pm 4.28$ & $350 \pm 1.60$ \\
\hline Week 10 & $326 \pm 2.67$ & $377.5 \pm 4.54$ & $327 \pm 3.74$ & $347.5 \pm 7.75$ \\
\hline Week 11 & $335 \pm 9.62$ & $367.5 \pm 1.34$ & $305 \pm 3 . .21$ & $346.5 \pm 3.47$ \\
\hline Week 12 & $344 \pm 8.02$ & $366.5 \pm 2.94$ & $311.5 \pm 9.35$ & $338.5 \pm 5 . .08$ \\
\hline Week 13 & $247.5 \pm 43.56$ & $276 \pm 46.5$ & $217 \pm 48.11$ & $253.5 \pm 48.37$ \\
\hline \multicolumn{5}{|c|}{ Post Recovery Period } \\
\hline Week 14 & $166.5 \pm 2.94$ & $192.5 \pm 1.34$ & $128 \pm 0.53$ & $156.5 \pm 4.01$ \\
\hline Week 15 & $171 \pm 3.21$ & $181 \pm 3.74$ & $132 \pm 0$ & $159.5 \pm 1.87$ \\
\hline Week 16 & $156.5 \pm 6.15$ & $180.5 \pm 2.41$ & $151.5 \pm 0.27$ & $142.5 \pm 1.87$ \\
\hline Week 17 & $160.9 \pm 1.60$ & $190.5 \pm 0.80$ & $136.5 \pm 0.27$ & $170.5 \pm 0.80$ \\
\hline
\end{tabular}

All values were expressed as Mean \pm S.E.M; $n=10$ 
Table 4. Effect of GCC on water intake $(\mathrm{ml})$ of experimental animals

\begin{tabular}{|l|l|l|l|l|}
\hline \multirow{2}{*}{ Weeks } & Treatment Groups & Group II & Group IV \\
\cline { 2 - 5 } & Group I & Group II & \\
\hline Treatment Period & $592.5 \pm 6.68$ & $600 \pm 0$ & $630.5 \pm 18.98$ & $625 \pm 2.67$ \\
\hline Week 1 & $615 \pm 29.40$ & $630 \pm 42.76$ & $567.5 \pm 14.70$ & $636 \pm 8.55$ \\
\hline Week 2 & $616.5 \pm 48.91$ & $674 \pm 23.52$ & $612.5 \pm 22.72$ & $664 \pm 34.21$ \\
\hline Week 3 & $747.5 \pm 14.70$ & $782.5 \pm 9.35$ & $690 \pm 21.38$ & $742.5 \pm 14.7$ \\
\hline Week 4 & $697.5 \pm 25.39$ & $670 \pm 42.76$ & $655 \pm 61.47$ & $705 \pm 45.43$ \\
\hline Week 5 & $775 \pm 8.02$ & $735 \pm 13.36$ & $725 \pm 13.36$ & $760 \pm 0$ \\
\hline Week 6 & $785 \pm 8.02$ & $780 \pm 10.69$ & $757.5 \pm 6.68$ & $775 \pm 13.36$ \\
\hline Week 7 & $795 \pm 2.67$ & $760 \pm 10.69$ & $730 \pm 16.04$ & $770 \pm 5.35$ \\
\hline Week 8 & $770 \pm 5.35$ & $730 \pm 10.69$ & $695 \pm 8.02$ & $730 \pm 0$ \\
\hline Week 9 & $795 \pm 2.67$ & $790 \pm 5.35$ & $765 \pm 2.67$ & $780 \pm 0$ \\
\hline Week 10 & $750 \pm 0$ & $760 \pm 0$ & $770 \pm 5.35$ & $760 \pm 10.69$ \\
\hline Week 11 & $925 \pm 24.05$ & $955 \pm 13.36$ & $835 \pm 29.40$ & $935 \pm 2.67$ \\
\hline Week 12 & $675 \pm 168.37$ & $675 \pm 136.30$ & $660 \pm 165.7$ & $645 \pm 157.68$ \\
\hline Week 13 & \multicolumn{5}{|l|}{} \\
\hline Post Treatment Period & $395 \pm 13.36$ & $435 \pm 8.02$ & $290 \pm 5.35$ & $335 \pm 2.67$ \\
\hline Week 14 & $305 \pm 8.02$ & $305 \pm 8.02$ & $270 \pm 0$ & $310 \pm 5.35$ \\
\hline Week 15 & $385 \pm 8.02$ & $425 \pm 2.67$ & $300 \pm 10.69$ & $315 \pm 2.67$ \\
\hline Week 16 & $355 \pm 18.71$ & $385 \pm 24.05$ & $260 \pm 5.35$ & $320 \pm 0$ \\
\hline Week 17 & All values were expressed as Mean \pm S.E.M; n=10 & \\
\hline &
\end{tabular}


Hematology results:

Table 5. Effect of GCC on Hematological parameters at $30^{\text {th }}$ day

\begin{tabular}{|l|l|l|l|l|}
\hline Parameter & Group I & Group II & Group III & Group IV \\
\hline Hb $(\mathbf{g} / \mathbf{d l})$ & $12.66 \pm 0.559$ & $12.71 \pm 0.398$ & $11.79 \pm 0.374$ & $12.43 \pm 0.191$ \\
\hline PCV $(\%)$ & $33.63 \pm 1.448$ & $33.77 \pm 1.085$ & $31.32 \pm 0.954$ & $32.94 \pm 0.507$ \\
\hline RBC (m/ $\boldsymbol{\mu l})$ & $6.906 \pm 0.282$ & $6.936 \pm 0.206$ & $6.520 \pm 0.209$ & $6.827 \pm 0.106$ \\
\hline WBC $(/ \mathbf{c m m})$ & $10285 \pm 900.6$ & $8881 \pm 687.7$ & $9800 \pm 660.1$ & $8553 \pm 575.8$ \\
\hline Platelets $(\mathbf{L} / \boldsymbol{\mu L})$ & $7.564 \pm 0.451$ & $7.038 \pm 0.491$ & $8.000 \pm 0.307$ & $7.888 \pm 0.244$ \\
\hline Neutrophils $(/ \mathbf{c m m})$ & $20.74 \pm 0.801$ & $18.50 \pm 1.072$ & $16.72 \pm 0.726$ & $18.84 \pm 0.693$ \\
\hline Lymphocytes $(/ \mathbf{c m m})$ & $74.11 \pm 0.884$ & $76.65 \pm 1.208$ & $79.63 \pm 0.780$ & $76.21 \pm 0.890$ \\
\hline Monocytes $(/ \mathbf{c m m})$ & $2.737 \pm 0.365$ & $2.550 \pm 0.328$ & $1.842 \pm 0.115$ & $2.526 \pm 0.377$ \\
\hline Eosinophils $(/ \mathbf{c m m})$ & $2.556 \pm 0.166$ & $2.350 \pm 0.181$ & $2.105 \pm 0.169$ & $2.474 \pm 0.177$ \\
\hline
\end{tabular}

All values were expressed as Mean \pm S.E.M; $n=10$

Table 6. Effect of GCC on Hematological parameters at $60^{\text {th }}$ day

\begin{tabular}{|c|c|c|c|c|}
\hline Parameter & Group I & Group II & Group III & Group IV \\
\hline Hb (g/dl) & $12.43 \pm 0.425$ & $11.47 \pm 0.235$ & $39.07 \pm 6.366$ & $38.05 \pm 8.067$ \\
\hline $\operatorname{PCV}(\%)$ & $33.55 \pm 1.224$ & $30.81 \pm 0.675$ & $29.73 \pm 1.037$ & $29.89 \pm 0.562$ \\
\hline $\mathrm{RBC}(\mathrm{m} / \boldsymbol{\mu l})$ & $6.702 \pm 0.258$ & $6.198 \pm 0.140$ & $6.029 \pm 0.209$ & $5.951 \pm 0.121$ \\
\hline $\mathrm{WBC}(/ \mathrm{cmm})$ & $9050 \pm 1087$ & $8055 \pm 494.5$ & $7595 \pm 421.9$ & $7625 \pm 647.0$ \\
\hline Platelets $(\mathrm{L} / \boldsymbol{\mu L})$ & $7.903 \pm 0.398$ & $8.219 \pm 0.277$ & $8.337 \pm 0.376$ & $8.389 \pm 0.254$ \\
\hline Neutrophils (/cmm) & $23.60 \pm 1.072$ & $21.75 \pm 1.135$ & $22.7 \pm 1.363$ & $24.38 \pm 1.064$ \\
\hline Lymphocytes (/cmm) & $69.80 \pm 2.677$ & $73.00 \pm 1.277$ & $72.75 \pm 1.442$ & $71.81 \pm 1.141$ \\
\hline
\end{tabular}




\begin{tabular}{|l|l|l|l|l|}
\hline Monocytes (/cmm) & $2.80 \pm 0.277$ & $2.90 \pm 0.190$ & $2.85 \pm 0.283$ & $2.25 \pm 0.111$ \\
\hline Eosinophils $(/ \mathbf{c m m})$ & $1.750 \pm 0.123$ & $1.850 \pm 0.150$ & $1.700 \pm 0.105$ & $1.800 \pm 0.144$ \\
\hline \multicolumn{7}{|c}{ All values were expressed as Mean \pm S.E.M; $n=10$} \\
\hline
\end{tabular}

Table 7. Effect of GCC on Hematological parameters at $90^{\text {th }}$ day

\begin{tabular}{|c|c|c|c|c|}
\hline Parameter & Group I & Group II & Group III & Group IV \\
\hline Hb (g/dl) & $11.21 \pm 0.381$ & $11.96 \pm 0.327$ & $11.92 \pm 0.207$ & $11.73 \pm 0.329$ \\
\hline PCV (\%) & $31.48 \pm 1.055$ & $33.92 \pm 0.945$ & $33.72 \pm 0.504$ & $33.12 \pm 0.863$ \\
\hline $\mathrm{RBC}(\mathrm{m} / \mu \mathrm{l})$ & $5.955 \pm 0.210$ & $6.286 \pm 0.218$ & $6.405 \pm 0.114$ & $6.248 \pm 0.178$ \\
\hline WBC (/cmm) & $9620 \pm 881.2$ & $8605 \pm 685.8$ & $8118 \pm 591.2$ & $15606 \pm 4731$ \\
\hline Platelets $(\mathbf{L} / \mu \mathbf{L})$ & $7.791 \pm 0.281$ & $8.481 \pm 0.287$ & $8.700 \pm 0.198$ & $8.549 \pm 0.340$ \\
\hline Neutrophils (/cmm) & $26.20 \pm 1.167$ & $42.25 \pm 18.75$ & $21.76 \pm 0.779$ & $26.50 \pm 1.049$ \\
\hline Lymphocytes (/cmm) & $69.4 \pm 1.148$ & $70.35 \pm 1.487$ & $73.94 \pm 0.829$ & $69.83 \pm 1.055$ \\
\hline Monocytes (/cmm) & $2.550 \pm 0.245$ & $3.400 \pm 0.515$ & $2.353 \pm 0.331$ & $4.167 \pm 1.681$ \\
\hline Eosinophils (/cmm) & $1.850 \pm 0.150$ & $2.100 \pm 0.160$ & $1.941 \pm 0.159+$ & $1.313 \pm 0.150$ \\
\hline
\end{tabular}

All values were expressed as Mean \pm S.E.M; $n=10$

Table 8. Effect of GCC on Hematological parameters at $120^{\text {th }}$ day

\begin{tabular}{|c|c|c|c|c|}
\hline Parameter & Group I & Group II & Group III & Group IV \\
\hline Hb (g/dl) & $10.42 \pm 0.494$ & $11.03 \pm 0.209$ & $10.84 \pm 0.527$ & $10.06 \pm 0.395$ \\
\hline $\operatorname{PCV}(\%)$ & $28.80 \pm 1.357$ & $31.27 \pm 0.322$ & $30.31 \pm 1.412$ & $28.65 \pm 1.057$ \\
\hline $\mathrm{RBC}(\mathrm{m} / \boldsymbol{\mu l})$ & $5.591 \pm 0.296$ & $5.851 \pm 0.156$ & $5.825 \pm 0.318$ & $5.450 \pm 0.240$ \\
\hline WBC (/cmm) & $7313 \pm 841.6$ & $8800 \pm 801.9$ & $7500 \pm 847.7$ & $8163 \pm 731.4$ \\
\hline Platelets $(\mathrm{L} / \boldsymbol{\mu L})$ & $7.274 \pm 0.447$ & $8.179 \pm 0.203$ & $7.575 \pm 0.436$ & $7.149 \pm 0.367$ \\
\hline Neutrophils (/cmm) & $23.75 \pm 1.556$ & $24.40 \pm 1.157$ & $22.50 \pm 0.823$ & $23.63 \pm 1.569$ \\
\hline Lymphocytes (/cmm) & $69.00 \pm 1.822$ & $68.80 \pm 1.519$ & $72.50 \pm 1.052$ & $69.88 \pm 1.608$ \\
\hline Monocytes (/cmm) & $5.500 \pm 0.566$ & $5.100 \pm 0.622$ & $3.375 \pm 0.532$ & $4.500 \pm 0.731$ \\
\hline
\end{tabular}

2020 July Edition | www.jbino.com | Innovative Association 
Eosinophils (/cmm) $1.750 \pm 0.250$

All values were expressed as Mean \pm S.E.M; $n=10$

Biochemical parameters:

Table 9. Effect of GCC on serum biochemistry $\left(30^{\text {th }}\right.$ day):

\begin{tabular}{|c|c|c|c|c|c|c|c|c|c|c|c|c|c|}
\hline 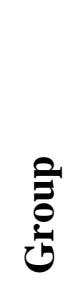 & 异 & 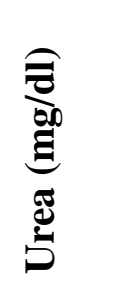 & 兽 & 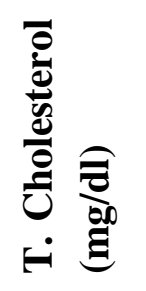 & 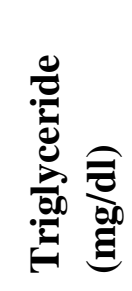 & 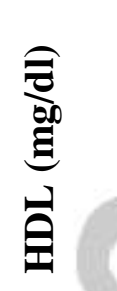 & 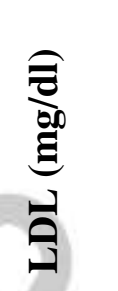 & 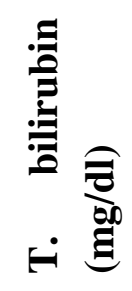 & 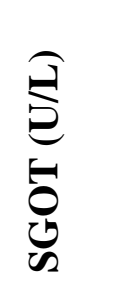 & 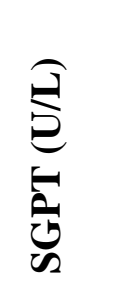 & 乎 & 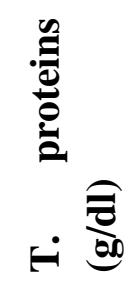 & 总 \\
\hline $\begin{array}{l}\text { G- } \\
\text { I }\end{array}$ & $\begin{array}{l}83.28 \\
\pm 5.42 \\
8\end{array}$ & $\begin{array}{l}30.50 \\
\pm 1.27 \\
9\end{array}$ & $\begin{array}{l}0.43 \pm \\
0.018\end{array}$ & $\begin{array}{l}79.17 \pm \\
3.853\end{array}$ & $\begin{array}{l}103.1 \\
\pm 6.02\end{array}$ & $\begin{array}{l}25 \pm 1 . \\
281\end{array}$ & $\begin{array}{l}32.22 \\
\pm 3.91 \\
6\end{array}$ & $\begin{array}{l}0.127 \\
\pm 0.01 \\
0\end{array}$ & $\begin{array}{l}227.6 \\
\pm 14.1 \\
4\end{array}$ & $\begin{array}{l}54.61 \\
\pm 1.94 \\
2\end{array}$ & $\begin{array}{l}167.2 \pm \\
12.06 \\
\end{array}$ & $\begin{array}{l}6.889 \\
\pm 0.09 \\
4\end{array}$ & $\begin{array}{l}8.367 \\
\pm 0.09 \\
0\end{array}$ \\
\hline $\begin{array}{l}\text { G- } \\
\text { II }\end{array}$ & $\begin{array}{l}87.83 \\
\pm 5.22 \\
7\end{array}$ & $\begin{array}{l}28.72 \\
\pm 1.21 \\
8\end{array}$ & $\begin{array}{l}0.43 \pm \\
0.016\end{array}$ & $\begin{array}{l}71.76 \pm \\
2.838\end{array}$ & $\begin{array}{l}85.29 \\
\pm 5.62 \\
9\end{array}$ & $\begin{array}{l}23.88 \\
\pm 0.97 \\
3\end{array}$ & $\begin{array}{l}32.29 \\
\pm 2.72 \\
1\end{array}$ & $\begin{array}{l}0.138 \\
\pm 0.01 \\
1\end{array}$ & $\begin{array}{l}214.6 \\
\pm 11.2 \\
9\end{array}$ & $\begin{array}{l}51.35 \\
\pm 3.58 \\
7\end{array}$ & $\begin{array}{l}194.8 \pm \\
14.46\end{array}$ & $\begin{array}{l}6.876 \\
\pm 0.11 \\
5\end{array}$ & $\begin{array}{l}8.341 \\
\pm 0.07 \\
8\end{array}$ \\
\hline $\begin{array}{l}\text { G- } \\
\text { III }\end{array}$ & $\begin{array}{l}98.63 \\
\pm 4.20 \\
4\end{array}$ & $\begin{array}{l}27.95 \\
\pm 1.22 \\
5\end{array}$ & $\begin{array}{l}0.38 \pm \\
0.024\end{array}$ & $\begin{array}{l}72.37 \pm \\
3.424\end{array}$ & $\begin{array}{l}95.37 \\
\pm 4.17\end{array}$ & $\begin{array}{l}23.63 \\
\pm 0.79 \\
9\end{array}$ & $\begin{array}{l}30.84 \\
\pm 3.22\end{array}$ & $\begin{array}{l}0.121 \\
\pm 0.00 \\
9\end{array}$ & $\begin{array}{l}183.9 \\
\pm 5.41 \\
4^{*}\end{array}$ & $\begin{array}{l}53.05 \\
\pm 1.48 \\
6\end{array}$ & $\begin{array}{l}205.4 \pm \\
15.54\end{array}$ & $\begin{array}{l}6.868 \\
\pm 0.11 \\
8\end{array}$ & $\begin{array}{l}8.374 \\
\pm 0.09 \\
5\end{array}$ \\
\hline $\begin{array}{l}\text { G- } \\
\text { IV }\end{array}$ & $\begin{array}{l}87.28 \\
\pm 5.19 \\
5\end{array}$ & $\begin{array}{l}26.11 \\
\pm 1 . \\
242\end{array}$ & $\begin{array}{l}0.42 \pm \\
0.018\end{array}$ & $\begin{array}{l}66.89 \pm \\
2.175^{*}\end{array}$ & $\begin{array}{l}87.53 \\
\pm 4.55 \\
9\end{array}$ & $\begin{array}{l}23.68 \\
\pm 0.78 \\
7\end{array}$ & $\begin{array}{l}28.32 \\
\pm 3.02 \\
7\end{array}$ & $\begin{array}{l}0.131 \\
\pm 0.01 \\
0\end{array}$ & $\begin{array}{l}175.5 \\
\pm 7.60 \\
5^{*}\end{array}$ & $\begin{array}{l}50.05 \\
\pm 2.08 \\
5\end{array}$ & $\begin{array}{l}197.7 \pm \\
12 . .41\end{array}$ & $\begin{array}{l}6.879 \\
\pm 0.10 \\
2\end{array}$ & $\begin{array}{l}8.379 \\
\pm 0.09 \\
5\end{array}$ \\
\hline
\end{tabular}

All values were expressed as Mean \pm S.E.M; $n=10$

* indicates $\mathrm{p}<0.05$ when compared to vehicle control 
Table 10. Effect of GCC on serum biochemistry ( $60^{\text {th }}$ day):

\begin{tabular}{|c|c|c|c|c|c|c|c|c|c|c|c|c|c|}
\hline हैं & 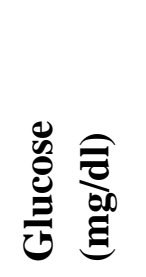 & 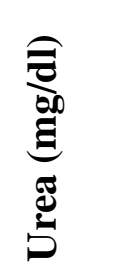 & & 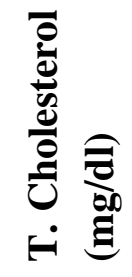 & 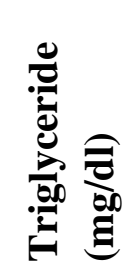 & 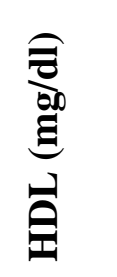 & 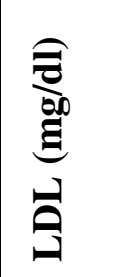 & 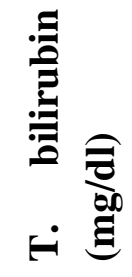 & 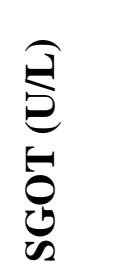 & $\underset{\vartheta}{\stackrel{\ominus}{2}}$ & 욜 & 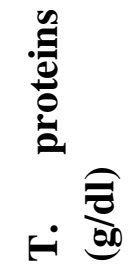 & 胥 \\
\hline $\begin{array}{l}\text { G- } \\
\text { I }\end{array}$ & $\begin{array}{l}109.4 \pm \\
3.363\end{array}$ & $\begin{array}{l}32.68 \\
\pm 1.47 \\
5\end{array}$ & $\begin{array}{l}0.494 \\
\pm 0.02 \\
2\end{array}$ & $\begin{array}{l}75.32 \\
\pm 3.35 \\
5\end{array}$ & $\begin{array}{l}103.6 \\
\pm 5.77 \\
1\end{array}$ & $\begin{array}{l}25.26 \\
\pm 1.03 \\
7\end{array}$ & $\begin{array}{l}29.16 \\
\pm 3.13 \\
7\end{array}$ & $\begin{array}{l}0.105 \\
\pm 0.00 \\
5\end{array}$ & $\begin{array}{l}191.7 \\
\pm 6.77 \\
6\end{array}$ & $\begin{array}{l}63.26 \\
\pm 2.34 \\
3\end{array}$ & $\begin{array}{l}225.6 \\
\pm 10.8 \\
1\end{array}$ & $\begin{array}{l}7.437 \\
\pm 0.08 \\
8\end{array}$ & $\begin{array}{l}9.57 \\
9 \pm 0 . \\
098\end{array}$ \\
\hline $\begin{array}{l}\text { G- } \\
\text { II }\end{array}$ & $\begin{array}{l}96.43 \pm \\
3.310\end{array}$ & $\begin{array}{l}32.05 \\
\pm 1.22 \\
\end{array}$ & $\begin{array}{l}0.476 \\
\pm 0.01\end{array}$ & $\begin{array}{r}68.33 \\
\pm 2.69 \\
\end{array}$ & $\begin{array}{l}100.1 \\
\pm 4.29\end{array}$ & $\begin{array}{l}22.76 \\
\pm 1.29 \\
\end{array}$ & $\begin{array}{l}25.52 \\
\pm 2.02 \\
\end{array}$ & $\begin{array}{l}0.110 \\
\pm 0.01\end{array}$ & $\begin{array}{l}221.7 \\
\pm 13.0 \\
\end{array}$ & $\begin{array}{l}66 \pm 3 \\
101\end{array}$ & $\begin{array}{l}242.8 \\
\pm 13.5\end{array}$ & $\begin{array}{l}7.310 \\
\pm 0.26\end{array}$ & $\begin{array}{l}9.55 \\
0 \pm 0 .\end{array}$ \\
\hline & & 4 & 5 & 2 & 0 & 6 & 0 & 0 & 6 & & 7 & 3 & 089 \\
\hline $\begin{array}{l}\text { G- } \\
\text { III }\end{array}$ & $\begin{array}{l}101.3 \pm \\
3.314\end{array}$ & $\begin{array}{l}34.44 \\
\pm 1.65 \\
9\end{array}$ & $\begin{array}{l}0.455 \\
\pm 0.02 \\
3\end{array}$ & $\begin{array}{l}67 \pm 3 \\
166\end{array}$ & $\begin{array}{l}91 \pm 4 \\
771\end{array}$ & $\begin{array}{l}22.33 \\
\pm 1.07 \\
9\end{array}$ & $\begin{array}{l}26.44 \\
\pm 2.92 \\
3\end{array}$ & $\begin{array}{l}0.105 \\
\pm 0.00 \\
5\end{array}$ & $\begin{array}{l}193.8 \\
\pm 7.91 \\
2\end{array}$ & $\begin{array}{l}57.11 \\
\pm 1.61 \\
5\end{array}$ & $\begin{array}{l}246.7 \\
\pm 10.8 \\
0\end{array}$ & $\begin{array}{l}7.050 \\
\pm 0.17 \\
1\end{array}$ & $\begin{array}{l}9.45 \\
6 \pm 0 \\
130\end{array}$ \\
\hline $\begin{array}{l}\text { G- } \\
\text { IV }\end{array}$ & $\begin{array}{l}93.68 \pm \\
3.295\end{array}$ & $\begin{array}{l}32.16 \\
\pm 1.19\end{array}$ & $\begin{array}{l}0.421 \\
\pm 0.02 \\
1\end{array}$ & $\begin{array}{l}61.16 \\
\pm 1.65 \\
3 \\
\end{array}$ & $\begin{array}{l}85.37 \\
\pm 4.69 \\
4\end{array}$ & $\begin{array}{l}21.11 \\
\pm 0.88 \\
8\end{array}$ & $\begin{array}{l}24.74 \\
\pm 1.73 \\
1\end{array}$ & $\begin{array}{l}0.100 \\
\pm 0.00\end{array}$ & $\begin{array}{l}177.5 \\
\pm 6.84 \\
5\end{array}$ & $\begin{array}{l}57.74 \\
\pm 2.76 \\
1 \\
\end{array}$ & $\begin{array}{l}234.2 \\
\pm 21.1 \\
2\end{array}$ & $\begin{array}{l}7.121 \\
\pm 0.07 \\
5\end{array}$ & $\begin{array}{l}9.50 \\
0 \pm 0 \\
080\end{array}$ \\
\hline
\end{tabular}

All values were expressed as Mean \pm S.E.M; $n=10$ 
Table 11. Effect of GCC on serum biochemistry $\left(90^{\text {th }}\right.$ day):

\begin{tabular}{|c|c|c|c|c|c|c|c|c|c|c|c|c|c|}
\hline 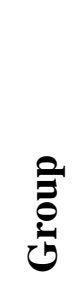 & 莺 & 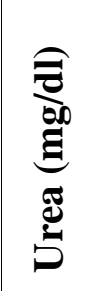 & 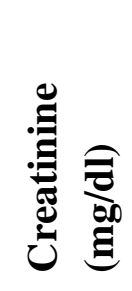 & 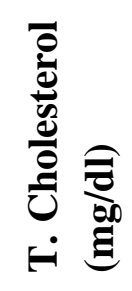 & 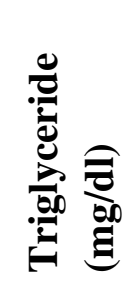 & 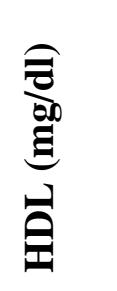 & 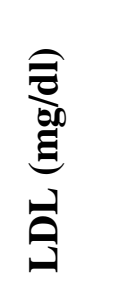 & 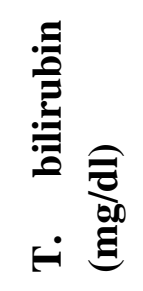 & $\underset{\vartheta}{\stackrel{\beta}{2}}$ & 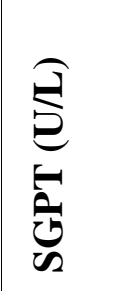 & 출 & 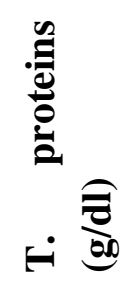 & 司 \\
\hline $\begin{array}{l}\text { G- } \\
\text { I }\end{array}$ & $\begin{array}{l}99 \pm 3.43 \\
2\end{array}$ & $\begin{array}{l}29.5 \\
8 \pm 1 \\
143\end{array}$ & $\begin{array}{l}0.463 \\
\pm 0.01 \\
5 \\
\end{array}$ & $\begin{array}{l}73 \pm 3 \\
196\end{array}$ & $\begin{array}{l}93.89 \\
\pm 6.43 \\
1\end{array}$ & $\begin{array}{l}28.84 \\
\pm 1.70 \\
0\end{array}$ & $\begin{array}{l}26.42 \\
\pm 3.65 \\
0\end{array}$ & \begin{tabular}{|l|}
0.115 \\
\pm 0.00 \\
8
\end{tabular} & $\begin{array}{l}172 \pm 8 \\
.520\end{array}$ & $\begin{array}{l}324.3 \\
\pm 268 \\
1\end{array}$ & $\begin{array}{l}156.4 \\
\pm 10.1 \\
0\end{array}$ & $\begin{array}{l}7.521 \\
\pm 0.06 \\
3\end{array}$ & $\begin{array}{l}9.39 \\
5 \pm 0 \\
144\end{array}$ \\
\hline $\begin{array}{l}\text { G- } \\
\text { II }\end{array}$ & $\begin{array}{l}95.25 \pm 3 \\
.298\end{array}$ & \begin{tabular}{|l|}
$27 \pm$ \\
0.74 \\
6 \\
\end{tabular} & $\begin{array}{l}0.450 \\
\pm 0.01 \\
1\end{array}$ & $\begin{array}{l}66.75 \\
\pm 3.10 \\
9 \\
\end{array}$ & $\begin{array}{l}73.3 \pm \\
3.608\end{array}$ & $\begin{array}{l}26.30 \\
\pm 1.51 \\
7\end{array}$ & $\begin{array}{l}25.40 \\
\pm 3.32 \\
6\end{array}$ & \begin{tabular}{|l}
0.120 \\
\pm 0.00 \\
9
\end{tabular} & $\begin{array}{l}182.9 \\
\pm 6.31 \\
1\end{array}$ & \begin{tabular}{|l}
51.85 \\
\pm 1.55 \\
5
\end{tabular} & $\begin{array}{l}154.2 \\
\pm 9.35 \\
6\end{array}$ & $\begin{array}{l}7.315 \\
\pm 0.11 \\
1\end{array}$ & $\begin{array}{l}8.87 \\
0 \pm 0 . \\
398\end{array}$ \\
\hline $\begin{array}{l}\text { G- } \\
\text { III }\end{array}$ & $\begin{array}{l}91.06 \pm 6 \\
.025\end{array}$ & \begin{tabular}{|l}
28.7 \\
$1 \pm 1$ \\
107 \\
\end{tabular} & $\begin{array}{l}0.438 \\
\pm 0.01 \\
4\end{array}$ & $\begin{array}{l}65.65 \\
\pm 2.76 \\
7\end{array}$ & $\begin{array}{l}84.82 \\
\pm 9.78 \\
5 \\
\end{array}$ & $\begin{array}{l}27.18 \\
\pm 1.80 \\
9\end{array}$ & $\begin{array}{l}23.53 \\
\pm 3.42 \\
9\end{array}$ & $\begin{array}{l}0.118 \\
\pm 0.01 \\
0\end{array}$ & $\begin{array}{l}173.3 \\
\pm 8.02 \\
1\end{array}$ & $\begin{array}{l}52.19 \\
\pm 2.01 \\
9\end{array}$ & $\begin{array}{l}171 \pm \\
11.73\end{array}$ & $\begin{array}{l}7.281 \\
\pm 0.10 \\
3\end{array}$ & $\begin{array}{l}8.98 \\
2 \pm 0 . \\
644\end{array}$ \\
\hline $\begin{array}{l}\text { G- } \\
\text { IV }\end{array}$ & $\begin{array}{l}100.6 \pm 1 \\
1.09\end{array}$ & $\begin{array}{l}32.1 \\
6 \pm 2 . \\
410\end{array}$ & $\begin{array}{l}0.447 \\
\pm 0.01 \\
1\end{array}$ & $\begin{array}{l}61.79 \\
\pm 2.10 \\
2 \\
\end{array}$ & $\begin{array}{l}76.72 \\
\pm 4.79 \\
6\end{array}$ & $\begin{array}{l}26.47 \\
\pm 1.97 \\
4\end{array}$ & $\begin{array}{l}20.32 \\
\pm 2.14 \\
3\end{array}$ & \begin{tabular}{|l}
0.126 \\
\pm 0.01 \\
0
\end{tabular} & $\begin{array}{l}182 \pm 6 \\
.749\end{array}$ & \begin{tabular}{|l}
54.11 \\
\pm 2.33 \\
8 \\
\end{tabular} & $\begin{array}{l}182.5 \\
\pm 14.8 \\
0\end{array}$ & $\begin{array}{l}7.368 \\
\pm 0.07 \\
6\end{array}$ & $\begin{array}{l}9.50 \\
0 \pm 0 . \\
088\end{array}$ \\
\hline
\end{tabular}

All values were expressed as Mean \pm S.E.M; $n=10$ 
Table 12. Effect of GCC on serum biochemistry $\left(\mathbf{1 2 0}^{\text {th }}\right.$ day $)$ :

\begin{tabular}{|c|c|c|c|c|c|c|c|c|c|c|c|c|c|}
\hline 官 & 莺 & 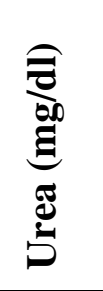 & & 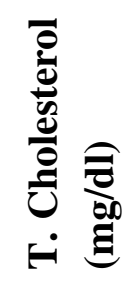 & 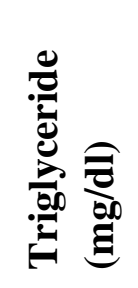 & 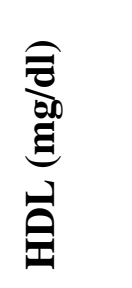 & 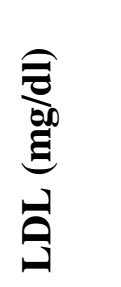 & 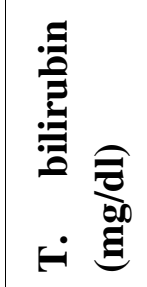 & $\underset{\vartheta}{\stackrel{\beta}{e}}$ & 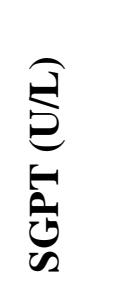 & $\underbrace{\beta}_{2}$ & $\dot{H}$ & 疍 \\
\hline $\begin{array}{l}\text { G- } \\
\text { I }\end{array}$ & $\begin{array}{l}97.67 \pm 5 \\
.180\end{array}$ & $\begin{array}{l}29.8 \\
9 \pm 1 \\
620\end{array}$ & $\begin{array}{l}0.422 \\
\pm 0.01 \\
4\end{array}$ & $\begin{array}{l}74.56 \\
\pm 3.57 \\
1\end{array}$ & $\begin{array}{l}93.22 \\
\pm 10.4 \\
4\end{array}$ & $\begin{array}{l}25.78 \\
\pm 1.16 \\
4\end{array}$ & $\begin{array}{l}30 \pm 4 . \\
327\end{array}$ & $\begin{array}{l}0.144 \\
\pm 0.01 \\
7\end{array}$ & $\begin{array}{l}186.6 \\
\pm 7.68 \\
0\end{array}$ & $\begin{array}{l}5311 \pm \\
3.195\end{array}$ & $\begin{array}{l}189.8 \\
\pm 19.4 \\
6\end{array}$ & $\begin{array}{l}6.456 \\
\pm 0.76 \\
6\end{array}$ & $\begin{array}{l}8.85 \\
6 \pm 0 \\
146\end{array}$ \\
\hline $\begin{array}{l}\text { G- } \\
\text { II }\end{array}$ & $\begin{array}{l}113.1 \pm 9 \\
.390\end{array}$ & $\begin{array}{l}29.3 \\
\pm 1.5\end{array}$ & $\begin{array}{l}0.480 \\
\pm 0.02\end{array}$ & $\begin{array}{l}76 \pm 2 . \\
996\end{array}$ & $\begin{array}{l}105.7 \\
\pm 9.43\end{array}$ & $\begin{array}{l}27 \pm 1 \\
011\end{array}$ & $\begin{array}{l}27.5 \pm \\
3.468\end{array}$ & $\begin{array}{l}0.100 \\
\pm 0.00\end{array}$ & $\begin{array}{l}206.7 \\
\pm 13.3\end{array}$ & $\begin{array}{l}56.7 \pm \\
1.535\end{array}$ & $\begin{array}{l}227.3 \\
\pm 40.6\end{array}$ & $\begin{array}{l}7.390 \\
\pm 0.13\end{array}$ & $\begin{array}{l}9.04 \\
0 \pm 0 .\end{array}$ \\
\hline
\end{tabular}




\begin{tabular}{|l|l|l|l|l|l|l|l|l|l|l|l|l|l|}
\hline & & 64 & 4 & & 2 & & & & 2 & & 5 & 2 & 164 \\
\hline G- & $103.1 \pm 1$ & $26 \pm$ & 0.428 & 75.29 & 89.14 & 26.43 & 31.29 & 0.100 & 193.9 & 52.57 & 215.7 & $7 \pm 0.1$ & 8.68 \\
III & 7.26 & 1.46 & \pm 0.01 & \pm 5.84 & \pm 17.6 & \pm 1.49 & \pm 7.47 & \pm 0.00 & \pm 15.9 & \pm 2.35 & \pm 40.6 & 89 & $6 \pm 0$. \\
& & 4 & 8 & 6 & 2 & 4 & 0 & & 8 & 9 & 5 & & 112 \\
\hline G- & $105.9 \pm 8$ & $29 \pm$ & 0.487 & $68 \pm 3$. & 95.38 & $22.5 \pm$ & 23.25 & 0.112 & 188.8 & 57.113 & 259.4 & 7.363 & 8.91 \\
IV & 138 & 0.96 & \pm 0.01 & 273 & \pm 7.73 & 0.944 & \pm 3.41 & \pm 0.01 & \pm 8.50 & \pm 2.21 & \pm 50.9 & \pm 0.10 & $2 \pm 0$. \\
& & 3 & 2 & & 2 & & 6 & 2 & 2 & 6 & 8 & 6 & 208 \\
\hline
\end{tabular}

All values were expressed as Mean \pm S.E.M; $n=10$

Macroscopic Observations:

Table13. Effect of GCC on Macroscopic Observations

\begin{tabular}{|c|c|c|c|c|}
\hline \multirow{3}{*}{$\begin{array}{l}\text { S. } \\
\text { No } \\
1\end{array}$} & \multirow{3}{*}{\begin{tabular}{|l|} 
Grou \\
p \\
G-I
\end{tabular}} & \multirow{3}{*}{$\begin{array}{l}\text { Total } \\
\text { No. of } \\
\text { Animals } \\
20\end{array}$} & \multicolumn{2}{|l|}{ Macroscopic Findings } \\
\hline & & & Terminal sacrifice & Post recovery sacrifice \\
\hline & & & NAO & $\begin{array}{l}\text { A cyst in left kidney (animal } \\
\text { No.GCC50; male). } \\
\text { Presence of black pores, pale colored } \\
\text { liver and kidneys (animal No.GCC58; } \\
\text { female). }\end{array}$ \\
\hline 2 & G-II & 20 & $\begin{array}{l}\text { Cystic ovary (animal } \\
\text { No.GCC18;female) }\end{array}$ & $\begin{array}{l}\text { Presence of black pores, pale colored } \\
\text { liver and kidneys (animal No. GCC55; } \\
\text { male). }\end{array}$ \\
\hline 3 & $\mathbf{G}$ & 20 & $\begin{array}{l}\text { Nodules at the base of the } \\
\text { pancreas (animal } \\
\text { No.GCC22; male) }\end{array}$ & $\begin{array}{l}\text { Cyst in left kidney (animal } \\
\text { No.GCC54; male). }\end{array}$ \\
\hline 4 & G-IV & 20 & NAO & NAO \\
\hline
\end{tabular}


Figure 1. Effect of GCC on histopathology of rat organs (at end of the treatment)

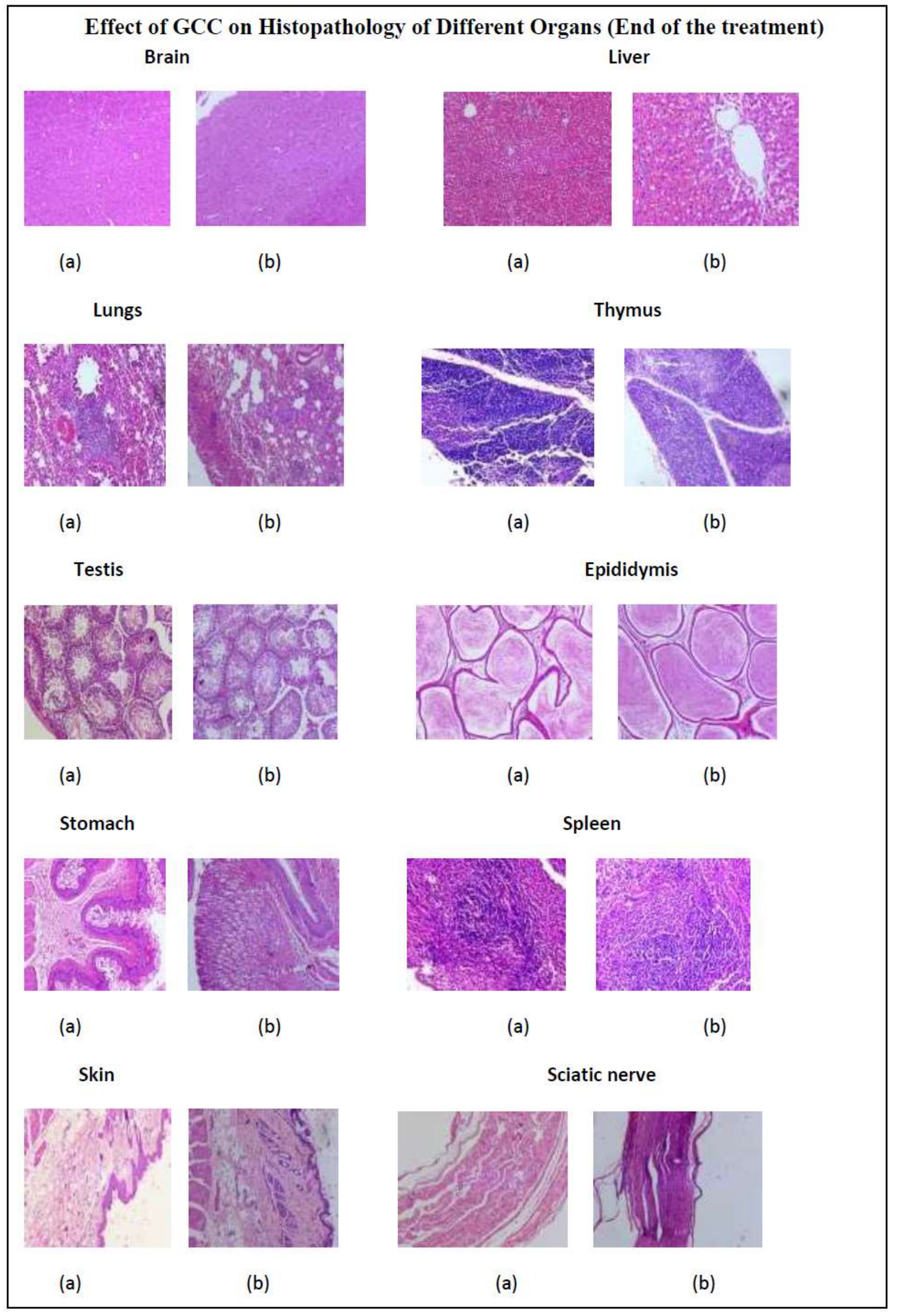




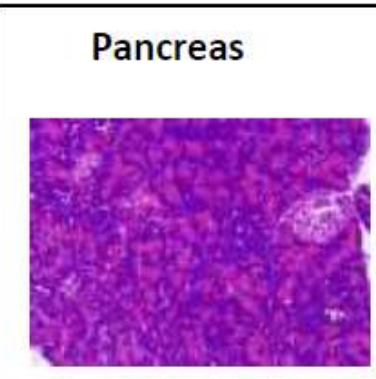

(a)

Heart

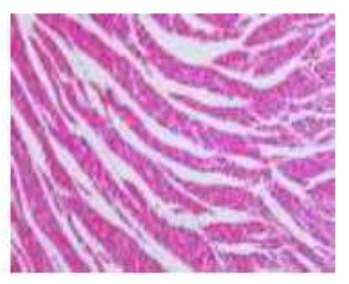

(a)

Adrenal gland

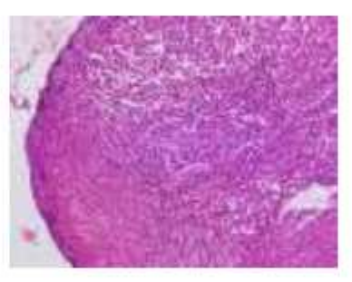

(a)

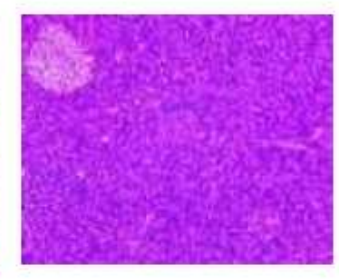

(b)

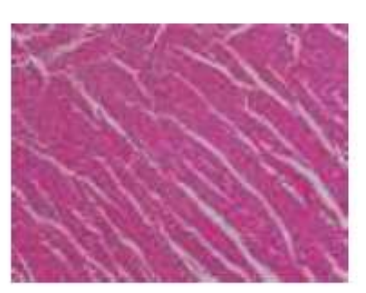

(b)

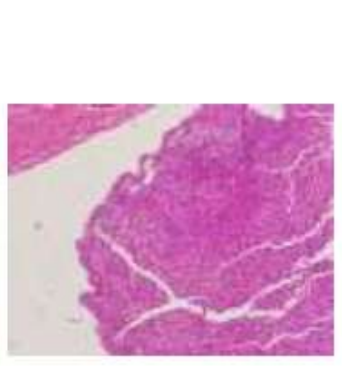

(b)

\section{Kidney}

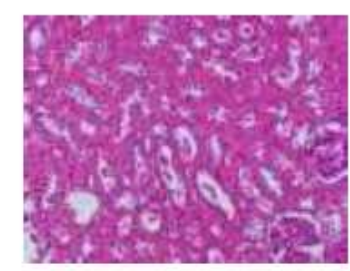

(a)

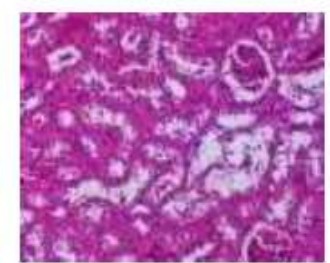

(b)

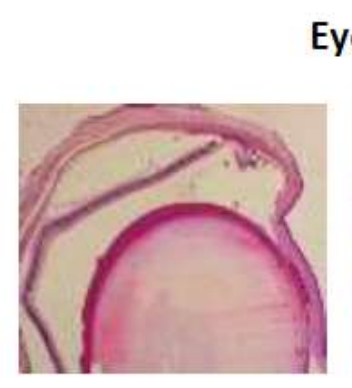

(a)

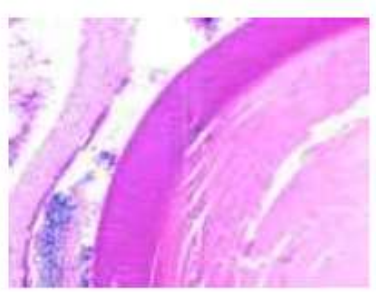

(b)

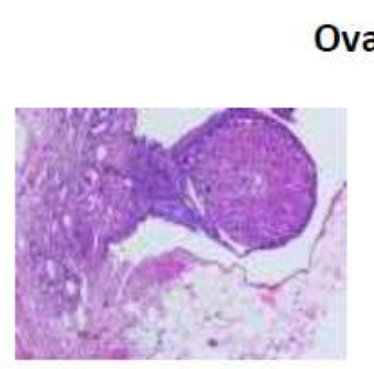

(a)

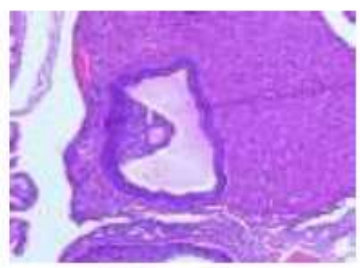

(b)

Uterus

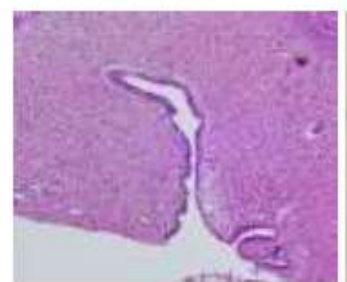

(a)

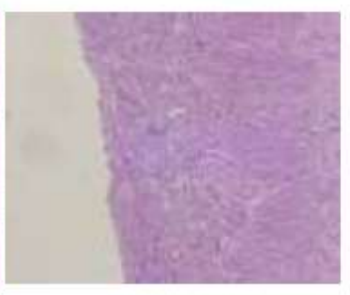

(b)

Microscope magnification: $10 \mathrm{X}$

(a)- denotes organs of the normal control animals

(b)- denotes organs of the animals treated with high dose of Gowri chinthamani chenduram 
Figure 2. Effect of GCC on histopathology of rat organs (Post recovery period)

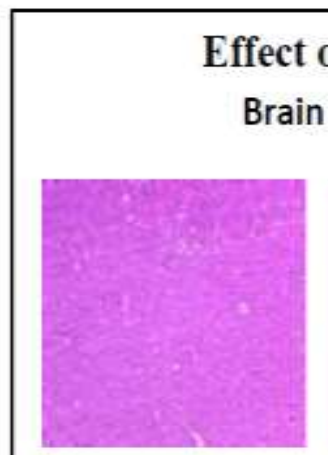

(a)

Lungs

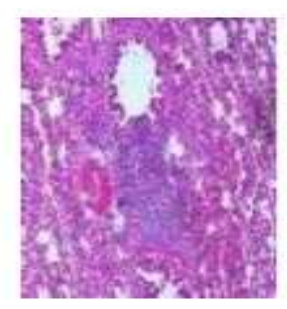

(a)

Testis

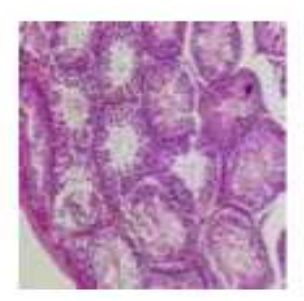

(a)

Stomach

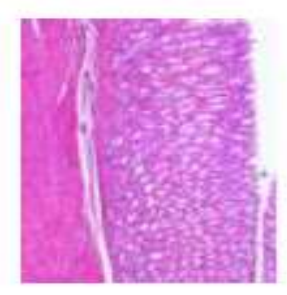

(a)

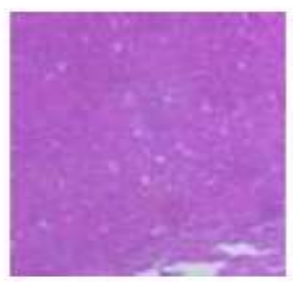

(b)

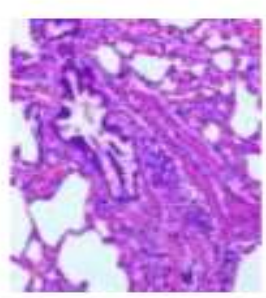

(b)

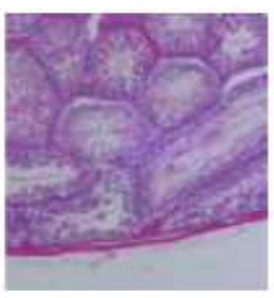

(b)

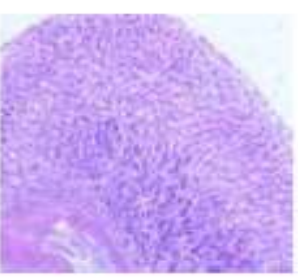

(b)

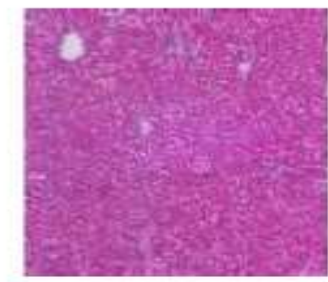

(a) Liver

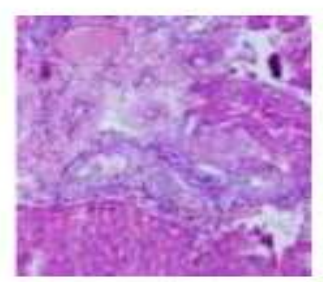

(b)

Thymus

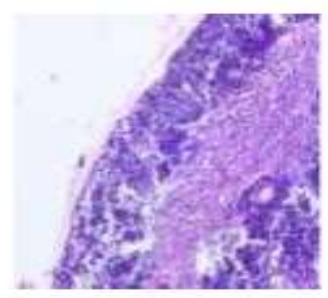

(a)

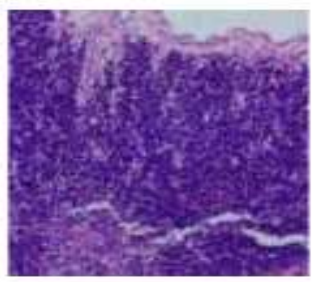

(b)

Epididymis

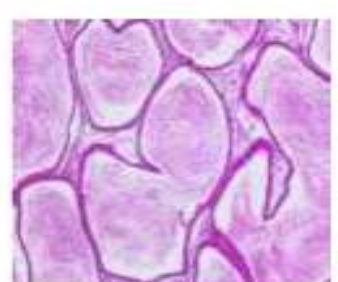

(a)

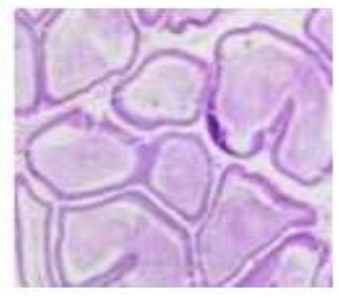

(b)

Spleen

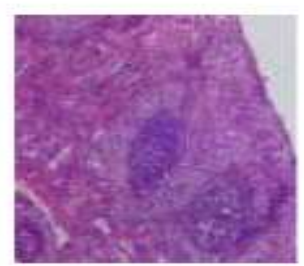

(a)

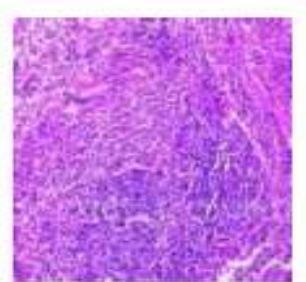

(b)

Skin

Sciatic nerve
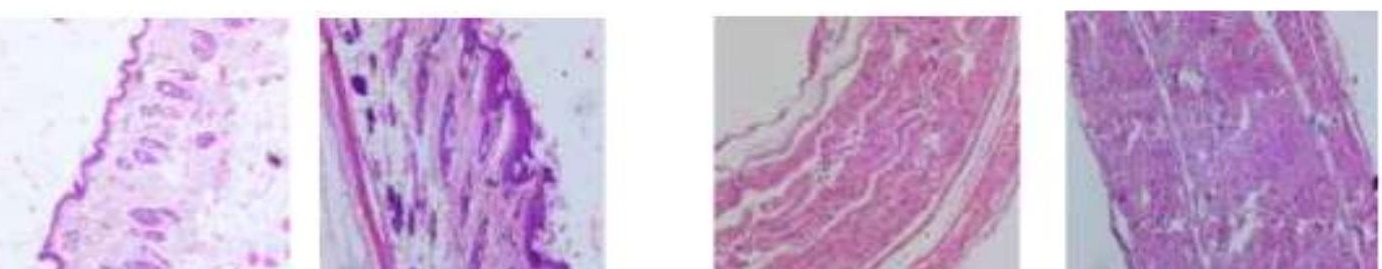


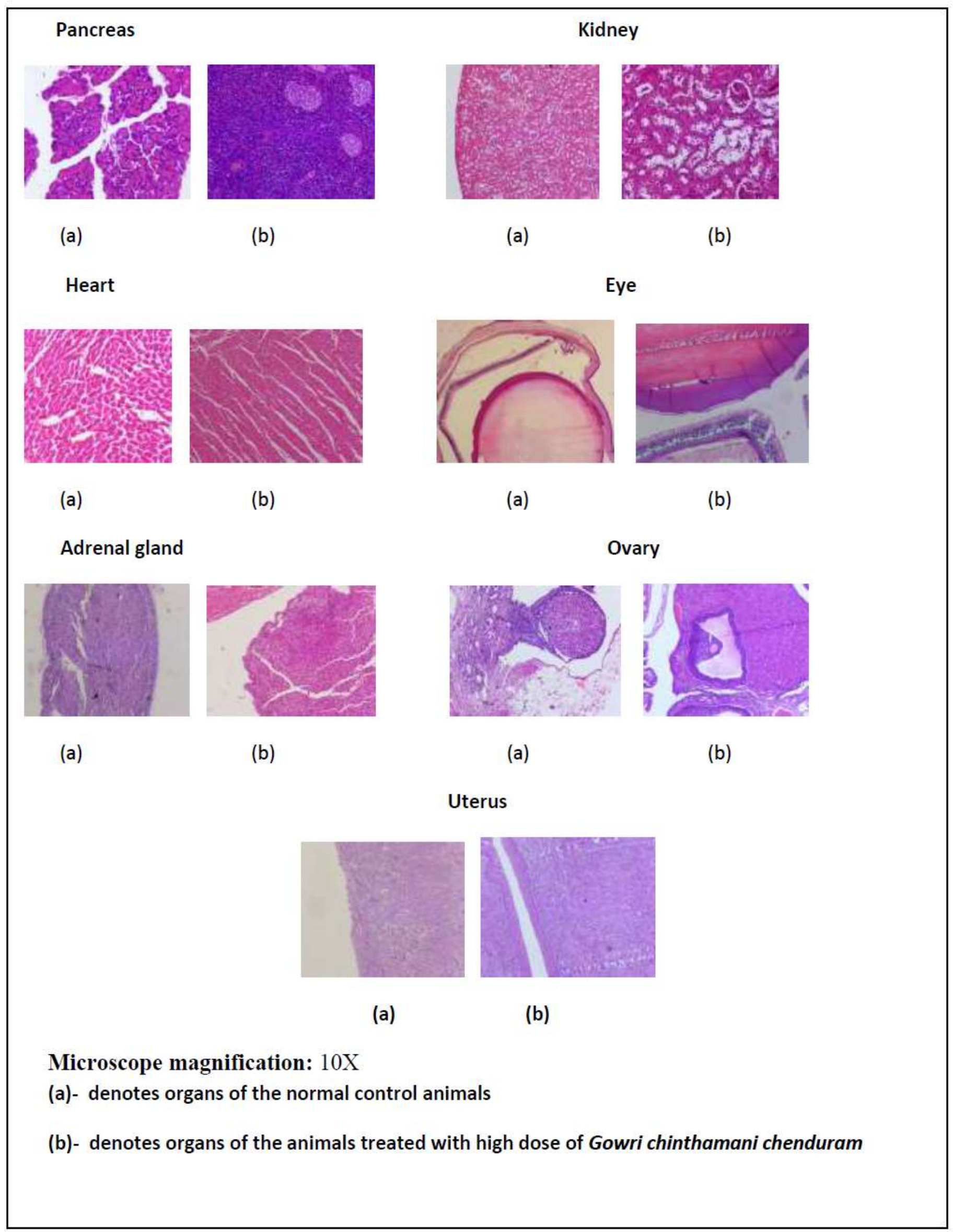

Microscope magnification: $10 \mathrm{X}$

(a)- denotes organs of the normal control animals

(b)- denotes organs of the animals treated with high dose of Gowri chinthamani chenduram 


\section{ACKNOWLEDGEMENT}

The present IMR-Project was sponsored by Central Council for Research in Siddha, Ministry of AYUSH, Arumbakkam, Chennai, Tamilnadu and the work has been carried out at Department of Pharmacology, Siddha Central Research Institute, Arumbakkam, Chennai.

\section{CONCLUSION:}

Under the conditions of the present study, daily oral administration of Gowri chinthamani chenduram at doses of up to $400 \mathrm{mg} / \mathrm{kg} /$ day was well tolerated in rats. The no-observed-adverse-effect-level (NOAEL) of Gowri chinthamani chenduram in rats is $>400 \mathrm{mg} / \mathrm{kg} /$ day when administered orally for 13 consecutive weeks (90 days).

\section{REFERENCES}

Madhavan $\mathbf{R}$, Sathish $\mathbf{R}$ and Murugesan M. standardization of Sangu parpam a herbo marine siddha drug. International Journal of Current Research in Chemistry and 1. Pharmaceutical Sciences. 2016; 3: 77-84.

Thas JJ. Siddha medicine-background and principles and the application for skin diseases. Clindermatol. 2008; 26:62-78.

Ravishankar B. and Shukla VJ. Indian systems of medicine: a brief profile. African Journal of Traditional, Complementary and Alternative medicines. 2007; 4: $319-337$.
Therapeutic index-Siddha. Published by SKM centre for Ayush Research and Education, $1^{\text {st }}$ ed. 2010; 134-144.

Ramachandran S.P, Agasthiar Vaidhya Kaviyam - 1500. Published by

Thamarai Publication, Chennai, 1 st ed. 1992; 195.

Velpandian V, Pitchiah Kumar $M$, Anbu N, Musthafa Md, Kanakavalli K. Clinical Evaluation of Siddha Drug Gowri Chinthamani Chenduram in the Management of Osteoarthritis. International Journal of Pharmaceutical Science Invention 2013; 2:26-32.

OECD (testing guideline, 408), 1998, Repeat dose 90 days oral toxicity study in rodents; In Guidance document for the development of OECD guideline for testing of chemicals Environmental monographs; This Test Guideline (TG) was updated in 2018.

FDA, Guidance for Industry: Estimating the Maximum Safe Starting Dose in Initial Clinical Trials for Therapeutics in Adult Healthy Volunteers, 2005.

Rafael Henrique Oliveira Lopes, Luis Fernando Benitez Macorini, Katia Ávila Antunes, Priscilla Pereira de Toledo Espindola, Tamaeh Monteiro Alfredo, Paola dos Santos da Rocha et al. "Antioxidant and Hypolipidemic Activity of the Hydro ethanolic Extract of Curatella americana L. Leaves". Oxidative Medicine and Cellular Longevity 2016. 